\title{
The Curing Process of Epoxy/Amino-Functionalized MWCNTs: Calorimetry, Molecular Modelling, and Electron Microscopy
}

\author{
S. G. Prolongo, M. R. Gude, and A. Ureña \\ Departamento Ciencia e Ingeniería de Materiales, ESCET, Universidad Rey Juan Carlos, C/ Tulipán s/n, Móstoles, \\ 28933 Madrid, Spain \\ Correspondence should be addressed to S. G. Prolongo, silvia.gonzalez@urjc.es
}

Received 5 July 2010; Accepted 8 September 2010

Academic Editor: Xiao Wei Sun

Copyright ( $\odot 2010$ S. G. Prolongo et al. This is an open access article distributed under the Creative Commons Attribution License, which permits unrestricted use, distribution, and reproduction in any medium, provided the original work is properly cited.

Curing kinetic of an epoxy resin reinforced with amino-functionalized MWCNTs has been studied by DSC and the obtained results were explained through morphological studies carried out by SEM, TEM, FEG-SEM, and molecular simulation tools. The presence of MWCNTs in the curing reaction induces a retardation effect of curing reaction and a decrease of the reaction heat. Both are associated with the adsorption of curing agent molecules inside carbon nanotubes, which was proved through the application of electron microscopic techniques and molecular simulation tools. It has been also demonstrated that there is a chemical reaction between amine groups anchored to the nanotubes and oxirane rings of epoxy monomer, which improves the nanoreinforcement/matrix interfacial adhesion, appearing a chemical interphase. The glass transition temperature $\left(T_{g}\right)$ of epoxy matrix increases by the addition of MWCNTs due to the restriction of its mobility.

\section{Introduction}

Epoxy resins are commonly used as polymeric matrices in high-performance composites. Carbon nanotubes (CNTs) are promising fillers to improve their mechanical, thermal and electrical behaviour [1, 2]. Numerous studies have been published about the fabrication and characterisation of CNT/epoxy nanocomposites [3-5]. The most of researches show moderate results regard to the theoretically expected ones. The properties of nanocomposites are improved regarding those showed by neat epoxy resins but they are not usually higher than the ones of conventional microscale composites. Poor dispersibility and high chemical inertness of as-synthesised carbon nanostructures can be the main processing limitations. In order to increase the compatibility between CNTs and epoxy matrix, an initiative consists on the introduction of polar groups on the surfaces of nanotubes $[6,7]$. The nanoreinforcements are covalent functionalized through reactive linker molecules, which can later react with functional groups of the matrix, providing interfaces of high covalent integrity. In particular, amino-functionalized CNTs are being widely investigated [8-10] as fillers of epoxy resins.
The thermal and mechanical characterisation of epoxy nanocomposites reinforced with amino-functionalized CNTs has been already tackled by several authors, showing some contrary results. In concrete, some works [9, 10] show that the glass transition temperature $\left(T_{g}\right)$ of epoxy matrix increases by the addition of amino-functionalized carbon nanotubes. This fact has been associated to the lower mobility of the epoxy moiety when it reacts with amino groups immobilized onto CNT surfaces. On the contrary, others researchers [8] have found that the $T_{g}$ of aminoCNT/epoxy nanocomposites decreases with regard to the one of neat epoxy resin. This effect has been justified by a change on the stoichiometric amine/epoxy ratio due to the introduction of amine groups anchored to nanotubes. Other published explanations are the incomplete crosslinking due to the possible acceleration effect by addition of aminofunctionalized CNTs or the adsorption of functional groups of epoxy prepolymer or curing agent into CNTs, leading to the inhibition of curing reaction between them. Even, it has been also published [8] that the soft segments of the linker molecules attached onto the surfaces of functionalized carbon nanotubes can give higher flexibility, making easier 
the matrix motion and therefore decreasing the $T_{g}$ of the nanocomposites. Taking into account the similar nature of the studied systems $[9,10]$, constituted by epoxy matrices reinforced with amino-functionalized multiwalled carbon nanotubes, it seems necessary to analyse the effect of the addition of amino-CNTs on the curing reaction of the epoxy resin and its influence on the glass transition temperature.

It is known that the presence of conventional carbon fibers scarcely affects to the curing kinetic of epoxy matrix [11]. However, the addition of carbon black and other small fillers to thermosetting polymer modifies its cure behaviour due to their higher specific area $[12,13]$. In fact, Kenny et al. $[14,15]$ have demonstrated that the carbon nanotubes also modify the curing kinetic of epoxy matrices.

The purpose of this study is to evaluate the influence of amino-functionalized carbon nanotubes on the curing kinetic of epoxy resin. For it, calorimetric studies, in scanning and isothermal mode, were carried out. In order to confirm the appearance of several phenomena, such as the chemical reaction between functionalized CNTs and epoxy monomer, the possible adsorption of monomers or the stoichiometry changes, different tests were planned, modifying the following parameters: the applied thermal treatment, the stoichiometric ratio and the percentage of amino-CNTs added. The drawn conclusions were confirmed through both, molecular simulation tools and electron microscopic studies.

\section{Experimental}

2.1. Materials. The epoxy monomer used was diglycidyl ether of bisphenol A (DGEBA) whose equivalent weight was $178 \mathrm{~g} /$ epoxy equivalent. As curing agent, 4,4'methylenedianiline (DDM), with a equivalent weight of $49.6 \mathrm{~g} /$ amine hydrogen was used. Both compounds were purchased from Sigma-Aldrich Chemical.

Multi-walled carbon nanotubes (MWCNTs) were purchased from Nanocyl (Belgian company), which were produced via Catalytic Carbon Vapour Deposition (CCVD) with a purity of $95 \%$. They were partially functionalized with amino groups $\left(0.5 \mathrm{wt} \% \mathrm{NH}_{2}\right.$ measured by the manufacturer).

2.2. Sample Preparation. Regarding the production of noncured mixtures, different mixing techniques in several stages were applied in order to get a suitable dispersion of the nanoreinforcements. The applied procedure was optimized in a previous work [16]. The carbon nanotubes were firstly dispersed in chloroform. Then, epoxy monomer was added to the solution, which was mixed by high shear mixing at $150 \mathrm{rpm}$ for 30 minutes at $45^{\circ} \mathrm{C}$. The resultant solution was then sonicated for 45 minutes at $45^{\circ} \mathrm{C}$ using a $50-60 \mathrm{~Hz}$ sonicator. Next, the solvent was evaporated by continuous stirring in vacuum at $90^{\circ} \mathrm{C}$ during 24 hours. Finally, DDM was added into the mixture, followed by stirring at $85^{\circ} \mathrm{C}$ for 3-5 minutes to dissolve the hardener. The amounts of CNTs added were 0.10 and $0.25 \%$ regard to epoxy monomer mass. Higher contents caused the appearance of large agglomerates of nanotubes [17].
The nonreinforced DGEBA/DDM mixture was prepared by the mixing of weighted amounts of both compounds at $85^{\circ} \mathrm{C}$ during 3 minutes. For each studied composition $(0$, 0.1 and $0.25 \mathrm{wt} \% \mathrm{CNTs}$ ), the mixtures were prepared with two different amine/epoxy ratios, $r=1.0$ and 1.2, where $r$ is determined as amine hydrogen equivalents per oxirane rings.

Other set of mixtures was fabricated following the same procedure but applying a previous precuring thermal treatment in the DGEBA/CNTs mixtures, before the addition of amine hardener. This treatment consisted on heating at $130^{\circ} \mathrm{C}$ for 1 hour. Its objective was to favour the chemical reaction between the amino groups of carbon nanotubes and oxirane rings of epoxy monomer before the curing reaction. The selected precuring temperature is enough high to promote the epoxy/amine reaction and enough low to avoid the noncatalysed homopolymerisation of DGEBA.

2.3. Characterisation. Calorimetric study of the curing behaviour of carbon nanofilled mixtures was performed using Setsys 16/18 differential scanning calorimeter (DSC). Indium, lead and tin were used to calibrate the calorimeter. The mixtures, with an approximate weight of $10 \mathrm{mg}$, were transferred to aluminium pans, which were subsequently covered by aluminium lids. Two different DSC studies were carried out in scanning and isothermal modes. The standard procedure performed in nonisothermal scans was a heating from 20 to $250^{\circ} \mathrm{C}$ at a scan rate of $10^{\circ} \mathrm{C} /$ minutes. Isothermal test consisted on heating at $100^{\circ} \mathrm{C}$ during 3 hours. After cooling, all studied samples were immediately subjected to DSC scan from 20 to $250^{\circ} \mathrm{C}$ at $10^{\circ} \mathrm{C} /$ minutes in order to determine the possible residual reaction heat and the glass transition temperature of cured epoxy nanocomposites. When the differences between the measured values for different samples were small, several measurements were repeated in order to confirm the data obtained.

The microscopic study of the MWCNTs and the cured nanocomposites was carried out with different electron microscopies: Scanning (ESEM), Transmission (TEM) and Field Emission Gun Scanning (FEG-SEM) Electron Microscopies. SEM images were captured with a Philips XL30 microscope. For it, the samples were sputter-coated with a thin layer of $\mathrm{Au}(\mathrm{Pd})$. The flexural fracture surfaces of samples were thinly coated with graphite for their observation by FEG-SEM, using Nova NanoSEM FEI 230. Finally, the observation by TEM was performed using Philips Tecnai 20 equipment over thin slices of samples. These were cut at $-100^{\circ} \mathrm{C}$ using an ultra-cryomicrotomer, Leica EMFCS instrument, equipped with a diamond knife.

Two different software of molecular simulation were used in order to analyse the geometry and size of the carbon nanotubes (Nanotube Modeler, JCrystalsoft version 1.5.0) and most stable configuration of molecules of DGEBA and DDM (Molecular Modeling Pro Plus version 6.2.5. from ChemSW).

\section{Results and Discussion}

Dynamic DSC thermograms of stoichiometric DGEBA/ DDM mixtures $(r=1)$ with different percentages of 
TABle 1: Summary of the dynamic DSC results.

\begin{tabular}{lcc}
\hline $\mathrm{wt} \% \mathrm{CNTs}$ & $\Delta H_{P}(\mathrm{~kJ} / \mathrm{ee})^{*}$ & $T_{P}\left({ }^{\circ} \mathrm{C}\right)^{* *}$ \\
\hline 0 & 92.3 & 175.6 \\
0.1 & 80.8 & 188.4 \\
0.25 & 88.8 & 179.1 \\
\hline \multicolumn{3}{c}{$r=1.2$} \\
\hline 0 & 109.0 & 178.1 \\
0.1 & 98.3 & 189.0 \\
0.25 & 105.2 & 176.5 \\
\hline \multicolumn{3}{c}{$r=1.0$} \\
& $* * *$ DGEBA/CNTs mixtures precured at $130{ }^{\circ} \mathrm{C}$ \\
\hline 0.1 & 78.2 & 187.5 \\
0.25 & 85.3 & 181.0 \\
\hline
\end{tabular}

${ }^{*} \Delta H_{P}(\mathrm{~kJ} / \mathrm{ee})$ : peak reaction heat in kilojoules per epoxy equivalent

${ }^{* *} T_{P}\left({ }^{\circ} \mathrm{C}\right)^{* *}$ : temperature of peak in Celsius

$* * *$ DGEBA/CNTs mixtures were heated at $130^{\circ} \mathrm{C}$ for 1 hour before the curing agent addition.

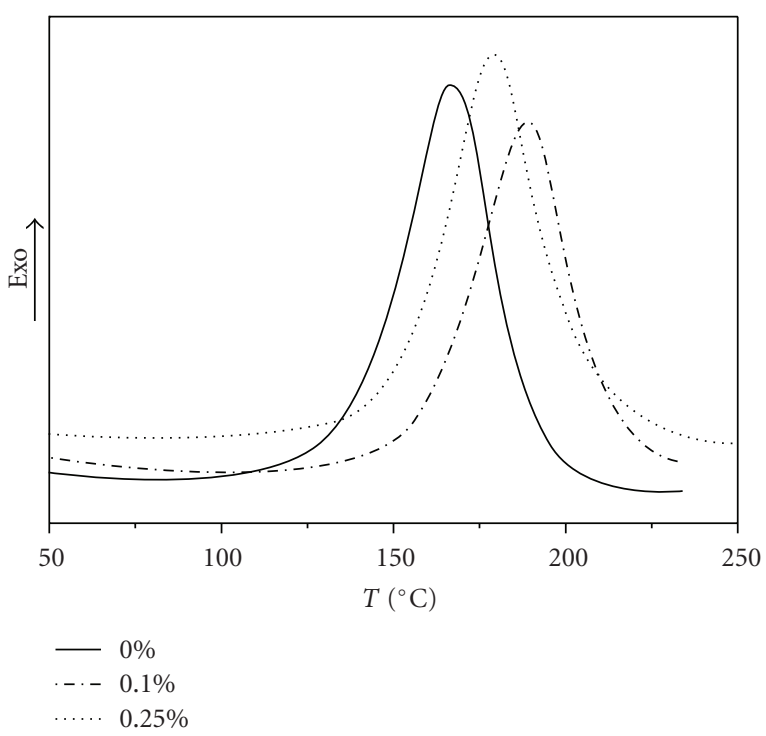

FIGURE 1: Dynamic DSC thermograms of stoichiometric mixtures $(r=1)$ with different amino-functionalized CNT content.

CNTs $(0,0.1,0.25 \mathrm{wt} \%)$ are presented in Figure 1. All the samples show only one exothermic peak corresponding to the epoxy/amine curing reaction. From these curves, two parameters were determined: (1) the maximum exothermal peak temperature $\left(T_{P}\right)$ and $(2)$ the reaction heat $\left(\Delta H_{P}\right)$ which was obtained integrating the area of exothermic DSC peak after baseline subtraction. In order to remove the dependence with the weight of sample, this parameter is normalized as function of the number of epoxide equivalents. Table 1 collects a summary of the dynamic DSC results.

The lower value measured for the stoichiometric DGEBA/DDM mixture, compared to the assumed theoretical value for epoxy/amine reaction enthalpy (close to $95-100 \mathrm{~kJ} / \mathrm{ee}$ ) is indicating that the epoxy network is not totally crosslinked, as it is common in the epoxy systems
$[18,19]$. Compared to the pure epoxy, a shift of exothermic peak to higher temperatures is observed in the composites. Meanwhile, the curing reaction heat of CNT/epoxy systems is lightly lower than one of neat epoxy resin. It is worthy to note that the higher differences are obtained for the epoxy resin reinforced with $0.1 \mathrm{wt} \%$. The studied sample with highest nanoreinforcement content shows an intermediate behaviour. The retardation effect of carbon nanotubes was already observed by other authors [12, 20, 21], such as Yang et al. [21] which studied the effect of amino-funtionalized CNTs on the curing reaction of DGEBA through homopolymerisation mechanism using an imidazole as initiator/catalyser. They explained it by the steric hindrance of the nanoreinforcements due to its very high-specific area $\left(\sim 300 \mathrm{~m}^{2} / \mathrm{g}\right)$. However, this explanation through diffusion problems is right when the curing reaction mechanism is by chain growth polymerisation, as epoxy homopolymerisation. The curing reaction mechanism of epoxy/amine system studied in this work is by step polymerisation where the diffusion control only occurs after vitrification. Therefore, the retardation effect can not be associated to reactive diffusion problems but to the adsorption of monomers into the nanotubes which modifies the mixture stoichiometry. This phenomenon has been already postulated by other authors $[22,23]$ and it will be analysed later in this work.

When the nanotubes concentration increases, the monomer adsorption effect on the cure reaction should be reinforced. However, at high nanoreinforcement contents, the obtained dispersion of nanofiller is worse, forming large aggregates [17] which cause a decrease of their effective surface area and therefore of their adsorption ability.

Figure 2 shows some micrographs captured by SEM, TEM and FEG-SEM which show the worse nanotube dispersion of epoxy nanocomposite reinforced with $0.25 \mathrm{wt} \%$ CNTs, where large agglomerations are observed with diameter higher than $1 \mu \mathrm{m}$.

The decrease of $\Delta H_{P}$ could have several explanations: (1) nonstoichiometric epoxy/amine balance due to the addition of amino-functionalized CNTs; (2) the physisorption of functional groups of epoxy prepolymer or curing agent, thus leading to the inhibition of crosslinking reaction between them [8]; (3) the covalent bonds between the amino groups immobilized on the nanotube sidewall and the epoxy prepolymers could reduce the mobility of chains of epoxy molecules, preventing to reach high conversions $[8,15]$.

In order to evaluate these assumptions, dynamic DSC studies were carried out in neat and nanoreinforced samples with an amine excess of 20\% $(r=1.2)$. The obtained results are also collected in Table 1 . Again, a $T_{P}$ increase and a $\Delta H_{P}$ decrease are measured for epoxy nanocomposites. Comparing both stoichiometries studied, the reaction heat increases with an amine excess while the peak temperature remains almost constant. The higher $\Delta H_{P}$ in samples with a small excess of amine groups has been already observed in other epoxy systems [24] and it is justified by some kind of catalysis through amine groups or by the different reactivity of the primary and secondary amines. 


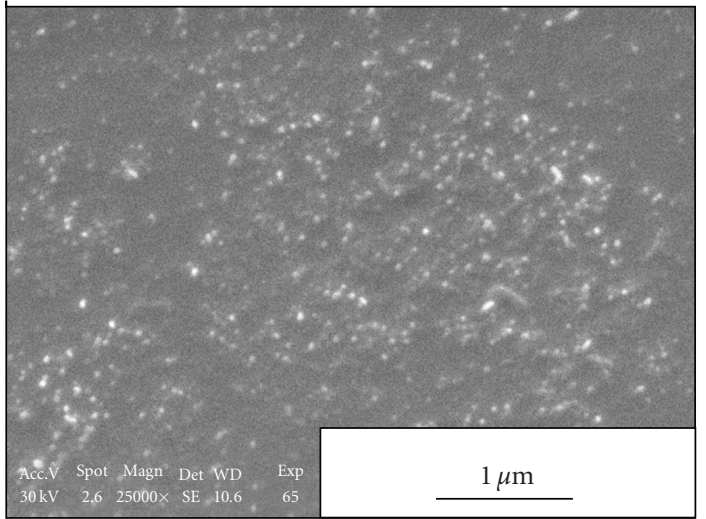

(a)

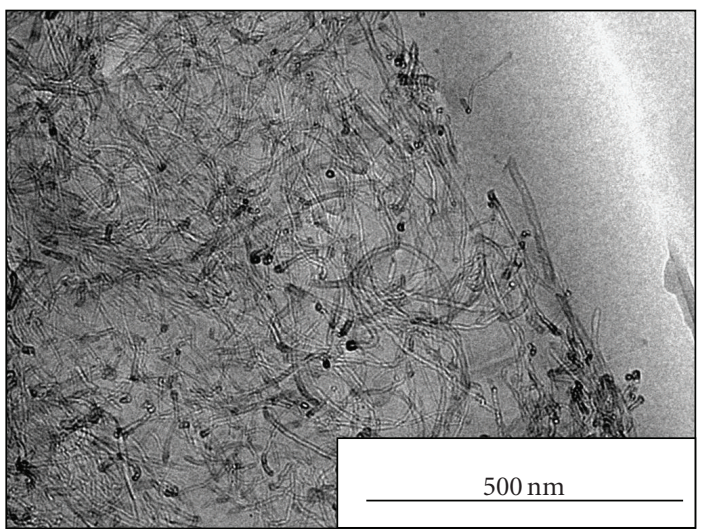

(c)

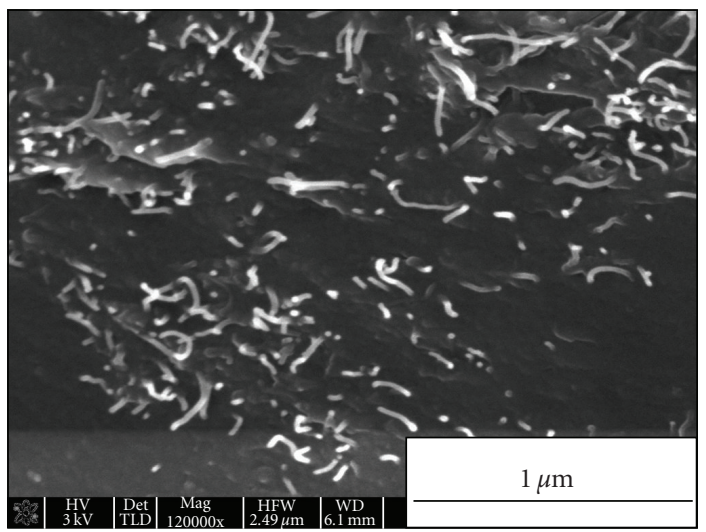

(e)

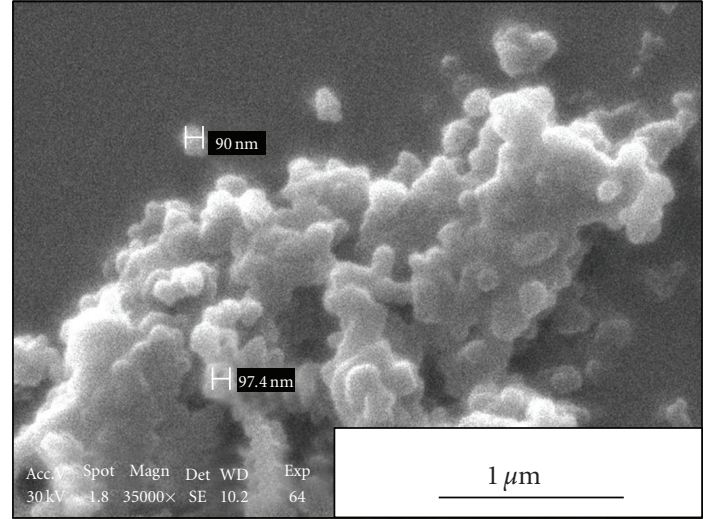

(b)

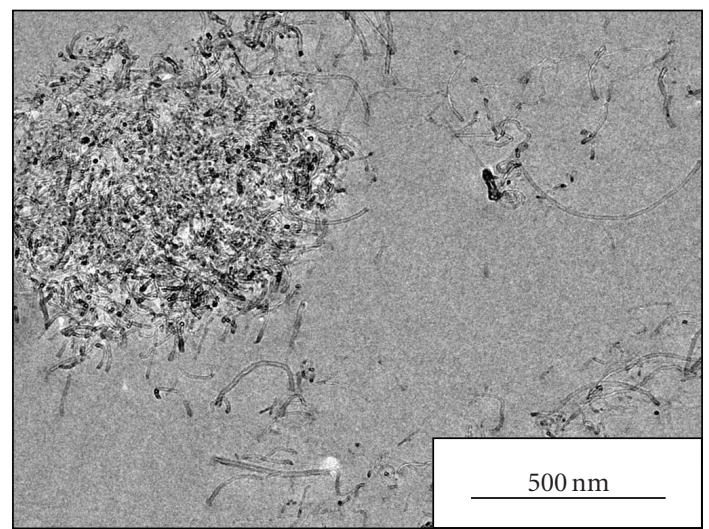

(d)

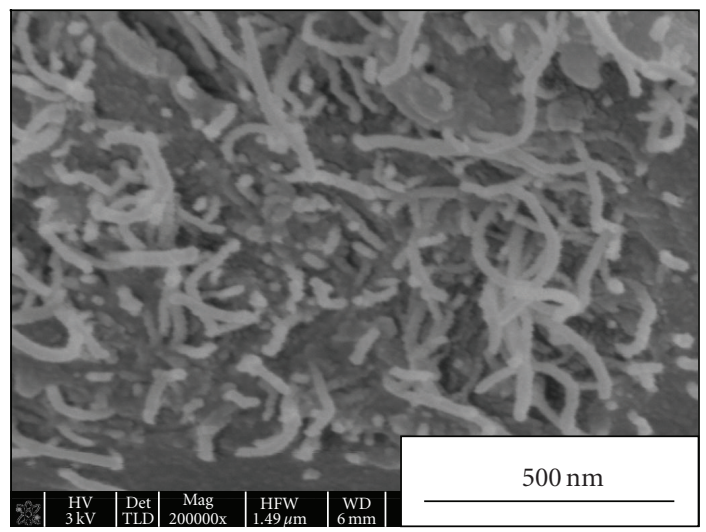

(f)

FIGURE 2: SEM, TEM and FEG-SEM micrographs of epoxy resin reinforced with 0.1 and 0.25 wt $\%$ CNTs: (a) SEM 0.1\%, (b) SEM 0.25\%, (c) TEM $0.1 \%$, (d) TEM $0.25 \%$, (e) FEG-SEM $0.1 \%$ and (f) FEG-SEM $0.25 \%$.

As it was just demonstrated, the curing reaction is improved by amine excess, therefore, for both studied stoichiometric ratios, the exothermic heat should increase or, at least, remain constant by the presence of aminofunctionalized CNTs. However, the results show the contrary behaviour. This implies that other phenomenon must be counteracting it. This could be the adsorption of molecules of amine hardener into carbon nanotubes, as it has been already postulated by other authors $[22,23]$. In fact, the kinetic results obtained by Valentini et al. [23] seem to confirm the possible adsorption of diethylenetriamine molecules into amine-functionalized single walled carbon nanotubes. In the present work, a study by molecular simulation has been carried out in order to determine the ability of adsorption of chemical molecules into multiwalled carbon nanotubes as function of the internal volume of MWCNTs and the most stable configurations of the molecules of DGEBA and DDM. 


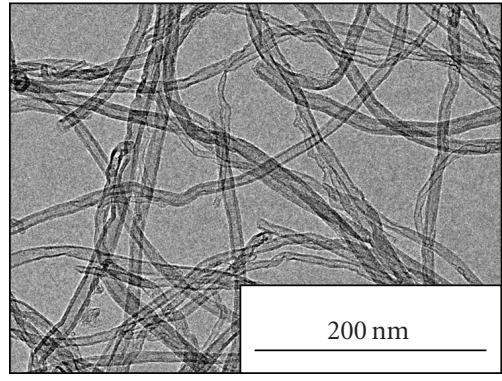

(a)

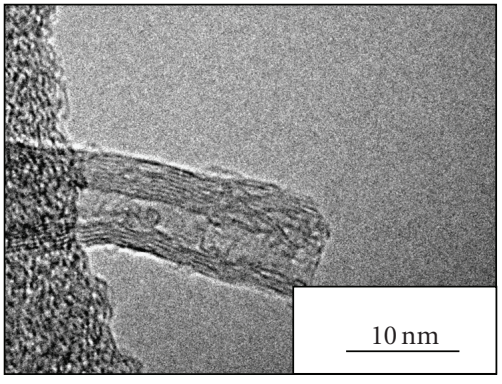

(b)

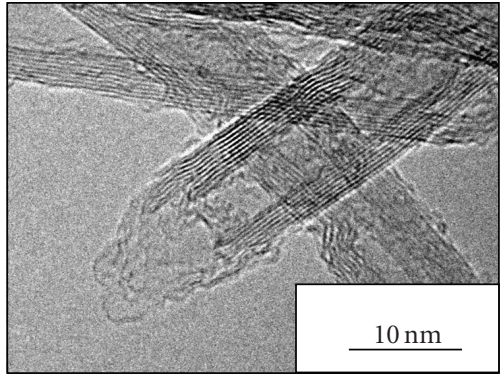

(c)

FIGURE 3: TEM micrographs of MWCNTs.

First, it was necessary to confirm that the used nanotubes were opened in their extremes and therefore that they were able to adsorb molecules inside them. Figure 3 shows TEM micrographs of MWCNTs used where it is observed this fact. The size and geometry of MWCNTs was determined by TEM using software of digital image analysis. Figure 4 confirms that the CNTs are constituted by 6-7 graphite walls and possess an average outside diameter of $9.59 \mathrm{~nm}$ and average internal diameter of $5.48 \mathrm{~nm}$. The average thickness of each wall is $0.348 \pm 0.008 \mathrm{~nm}$. The length of CNTs could not be measured with the available techniques, being around $1 \mu \mathrm{m}$ according to the manufacturer. Figure 5 shows a drawing to scale of carbon nanotubes used. Then, the size and geometry of the molecules and nanotubes were studied in order to determine if the molecules could go into the nanotubes. Through software of molecular simulation the most stable configurations of the molecules were determined in order to know their real dimensions (Figure 6). It is revealed that both molecules, DGEBA and DDM, could be adsorbed by the nanotubes although the lower size and high simplicity of the DDM molecules makes easier its preferential adsorption. Finally, the microscopic studies of cured epoxy nanocomposites by TEM (Figure 7) reveal the presence of matter into the carbon nanotubes, confirming the adsorption phenomenon. Figure 7(b) was analysed with specific image software. A study of the frequency distribution in the image (Figure 7(c)) confirms the presence of organic substances into the MWCNTs.

DDM adsorption into CNTs justifies the lower value measured for curing heat of nanocomposites but the shift of the peak temperature must be associated to the mobility restriction of epoxy chain molecules when they react with the amine groups anchored on the CNTs surfaces. In order to show this affirmation, a dynamic DSC study was carried out on precured samples. The precuring treatment consisted on the heating of the DGEBA/CNTs mixtures before DDM addition in order to favour the chemical reaction between epoxy prepolymer and amino-functionalized CNTs. The results are also shown in Table 1.

Firstly, it is confirmed the same observations that in the previous DSC studies, an increase of $T_{P}$ and a decrease of $\Delta H_{P}$ for the nanoreinforced epoxy resins. The lower exothermic heat measured for precured samples compared with that of nonprecured mixtures clearly indicates that there is chemical reaction between the oxirane rings of DGEBA and the amino groups of functionalized CNTs. This fact, which has been already confirmed by viscosity measurements in a previous work [17], is important for enhancing the load transfer from the matrix to the nanoreinforcements. The decrease of $\Delta H_{P}$ associated to the epoxy/CNTs precuring is so small because the number of amine groups attached to nanotubes is very low. The studied samples have 0.25 and $0.10 \%$ nanotubes regard to epoxy mass and these nanotubes only have $0.5 \mathrm{wt} \%$ of amine groups. In fact, it was not possible to measure directly the heat reaction between epoxy monomer and functionalized CNTs by DSC.

The effect of the precuring thermal treatment in the morphology of the fractured nanocomposites was determined by FEG-SEM. Figure 8 shows fractographies captured by FEG-SEM of two samples formed by epoxy-nanocomposite with $0.25 \mathrm{wt} \%$ CNTs where one of them was subjected to precuring treatment at $130^{\circ} \mathrm{C}$ for 1 hour before the addition of the DDM crosslinker. The analysed surfaces correspond with the fractures by flexural test. The nanocomposites present smooth surfaces with well-distributed nanotubes pullout. The main difference between both is the length of the nanotubes pull out. The nonprecured sample shows large segments of nanotubes pull out while the length of nanotube sticking out the surface on the precured nanocomposite is meaningfully shorter. This could indicate the formation of a stronger bond between the matrix and MWCNTs in the precured samples. As it is schematically indicated in the Figure $8(\mathrm{a})$, in the precured nanocomposite, the failure has propagated across the whole section, which is named fracture mode of the weakest link. It is known [25] that this only occurs when the filler is very strongly bonded to the matrix and the matrix is very brittle, such the epoxy resin. In fact, it seems that, at very high magnifications (Figures $8(\mathrm{~b})$ and $8(\mathrm{c})$ ), the nanotubes in precured samples are strongly joined to the matrix. In contrast, the nonprecured sample (Figures $8(\mathrm{e})$ and $8(\mathrm{f}))$ shows longer nanotubes over the fracture surface due to debonding and filler pull out, indicating a weaker interface.

The effect of amino-functionalized CNTs on the cure of epoxy resin was also analyzed by isothermal DSC experiments at $100^{\circ} \mathrm{C}$, whose results are shown in Table 2. The time at which the reaction heat is maximum $\left(t_{P}\right)$ is longer for epoxy nanocomposites, confirming the 


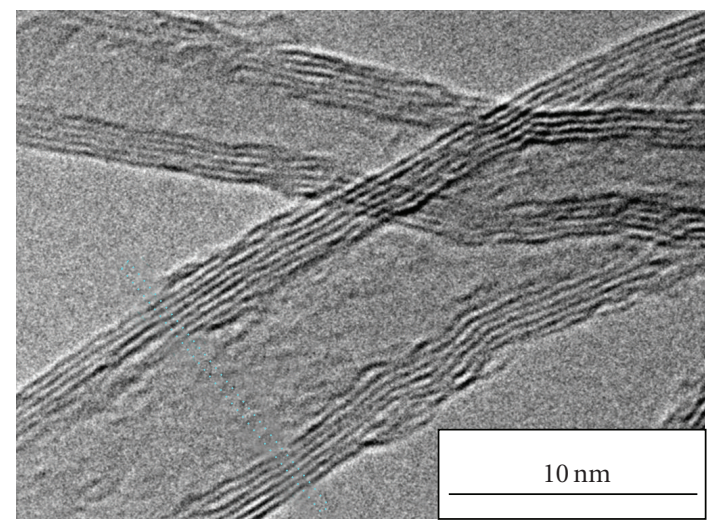

(a)

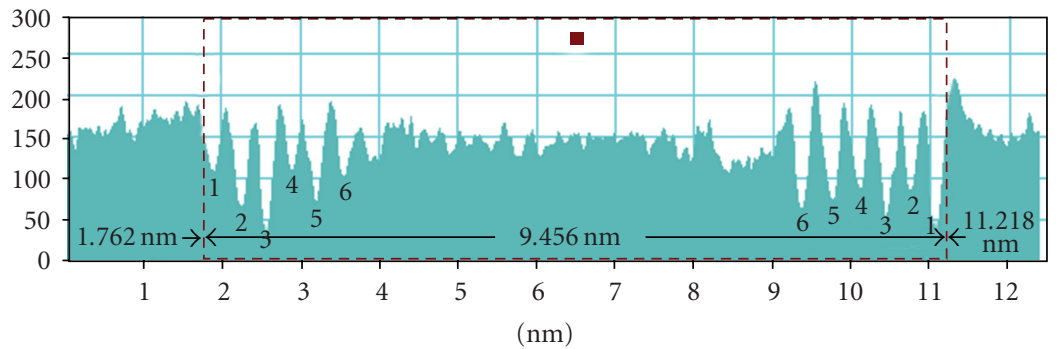

(b)

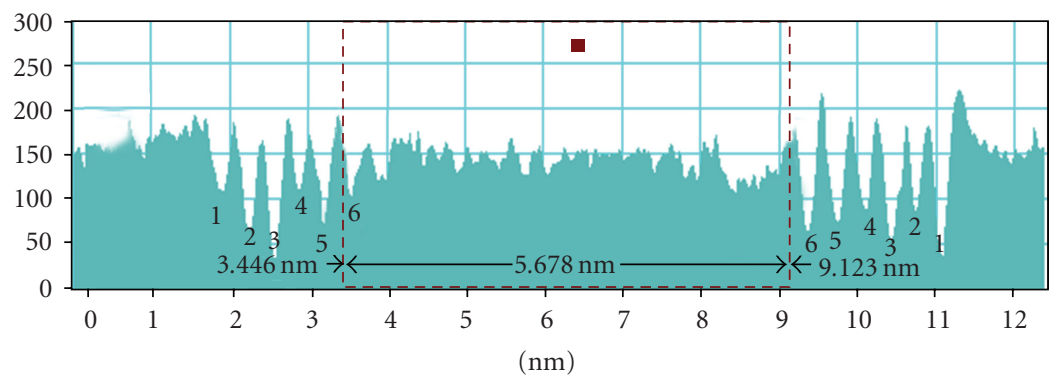

(c)

FIgURE 4: TEM micrograph of MWCNTs (a) and digital image analysis to measure its outside diameter (b) and inside diameter (c).

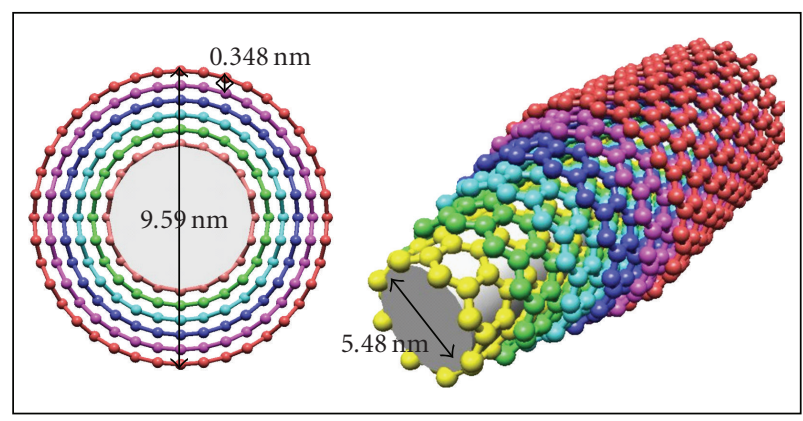

FIgURE 5: Multiwalled carbon nanotubes.

retardation effect caused by the presence of CNTs. Again, this effect is more marked when the amount of CNTs added is low, $0.1 \mathrm{wt} \%$. However, in these conditions, nonrelevant effects of nanotube addition on the reaction heat were
TABLE 2: Summary of the isothermal DSC results at $100^{\circ} \mathrm{C}$.

\begin{tabular}{lcc}
\hline wt\% CNTs & $\Delta H_{P}(\mathrm{~kJ} / \mathrm{ee})^{*}$ & $t_{P}(\mathrm{~min})^{* *}$ \\
\hline 0 & $r=1.0$ & \\
\hline 0.1 & 83.3 & 53.6 \\
0.25 & 81.4 & 55.6 \\
\hline
\end{tabular}

${ }^{*} \Delta H_{P}(\mathrm{~kJ} / \mathrm{ee})$ : peak reaction heat in kilojoules per epoxy equivalent $* * t_{P}(\min )$ : peak time in minutes.

detected. Similar observations were reported by Valentini et al. [14], who studied the cure behaviour of DGEBA using an aliphatic amine as hardener and $5 \mathrm{wt} \%$ single walled carbon nanotubes as nanoreinfocements. Also, these results confirm again that the lower $\Delta H_{P}$ of nanocomposites is mainly related with the adsorption of amine hardener inside the carbon nanotubes. At $100^{\circ} \mathrm{C}$, the neat epoxy resin does not reach a high crosslinking degree due to 


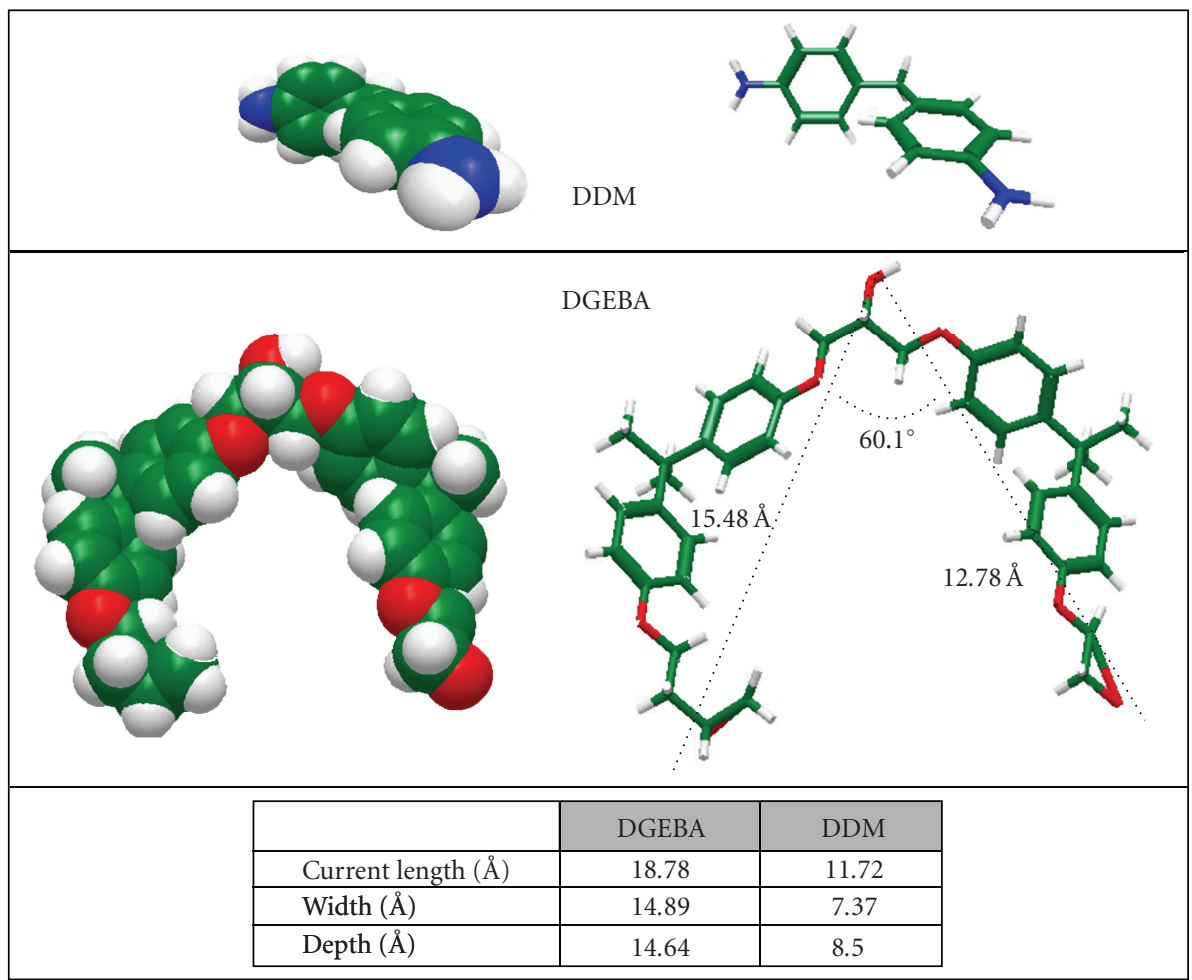

Figure 6: The most stable configurations of DGEBA and DDM.

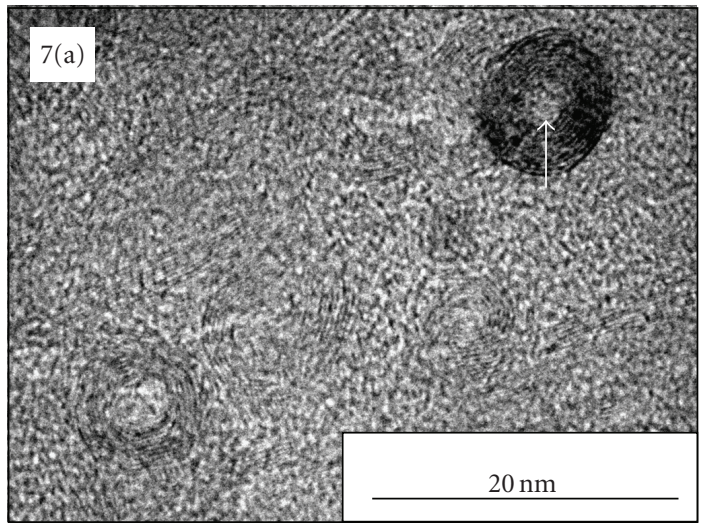

(a)

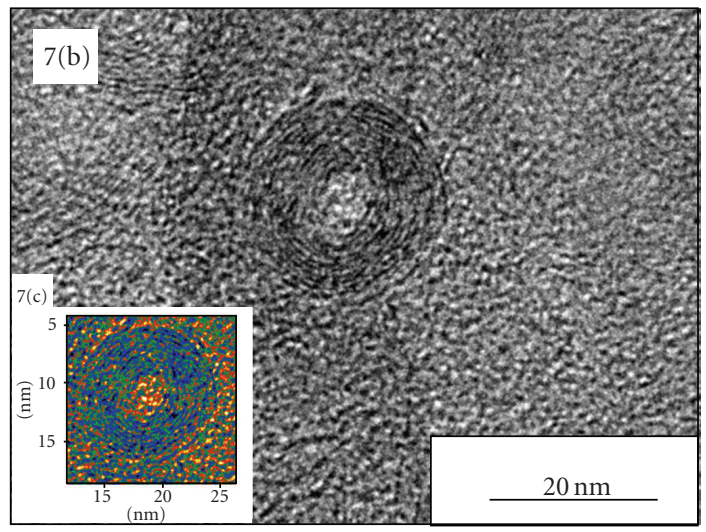

(b)

FIGURE 7: TEM micrographs of cured epoxy nanocomposites ( $a, b)$ and image analysis of frequency distributions (c).

the vitrification phenomenon, which occurs when its glass transition temperature reaches the curing temperature. This is why the adsorption of DDM molecules into CNTs scarcely affects to the isothermal cure since a high conversion is not reached.

The reaction rate, $d \alpha / d t$, is directly proportional to the rate of heat generation, $d H / d t$ :

$$
\frac{d \alpha}{d t}=\frac{1}{\Delta H_{P}} \frac{d H}{d t}
$$

The reaction extension, $\alpha$, can be determined by:

$$
\alpha=\frac{\Delta H_{t}}{\Delta H_{P}}
$$

where $\Delta H_{t}$ is the partial area under DSC trace up to time $t$.

Figure 9 shows the reaction rate versus time for the studied samples. The form of these curves is common in the isothermal cure of neat epoxy resins [26] and even carbon fiber reinforced epoxy materials [11]. The maximum reaction rate is observed at nonzero time, meaning that the 


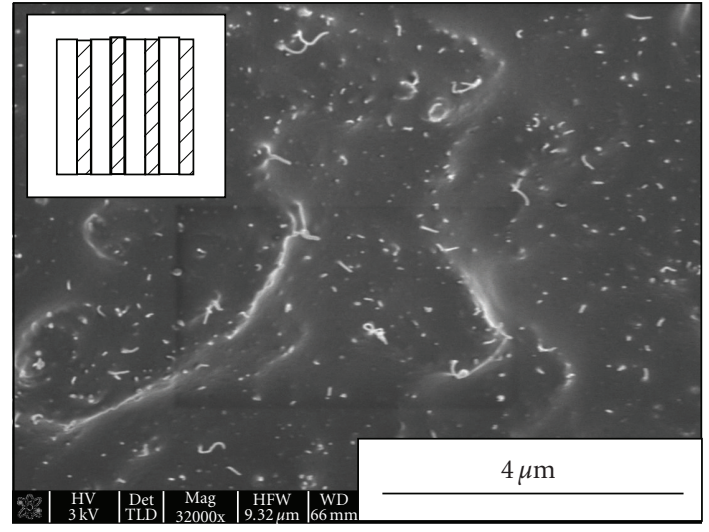

(a)

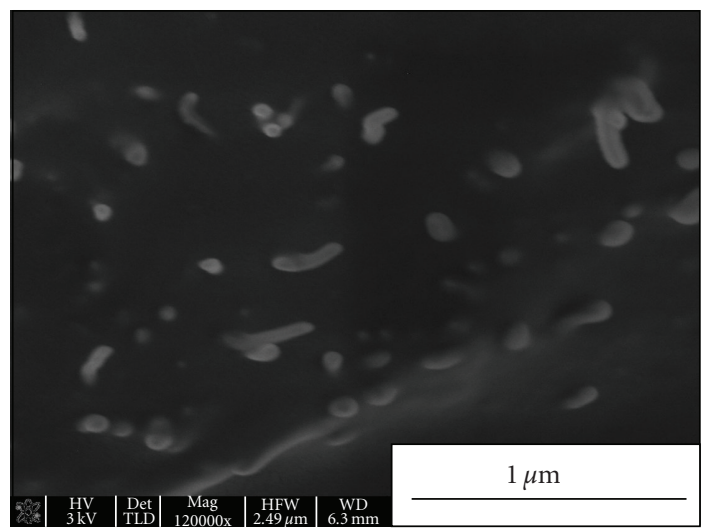

(c)

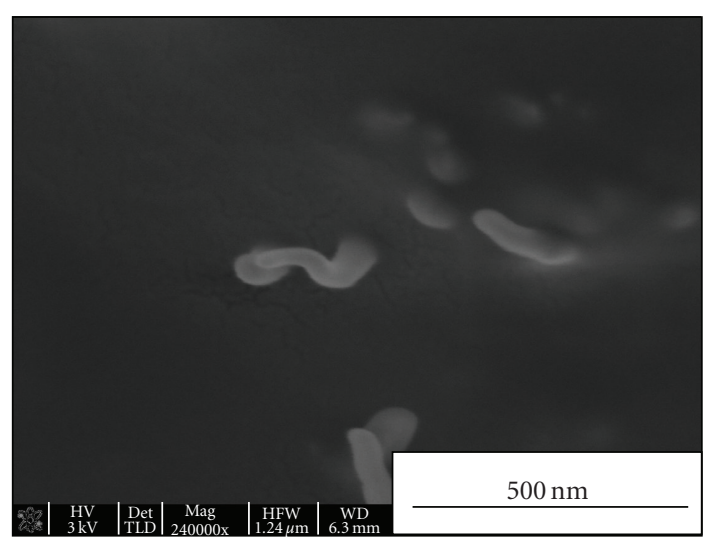

(e)

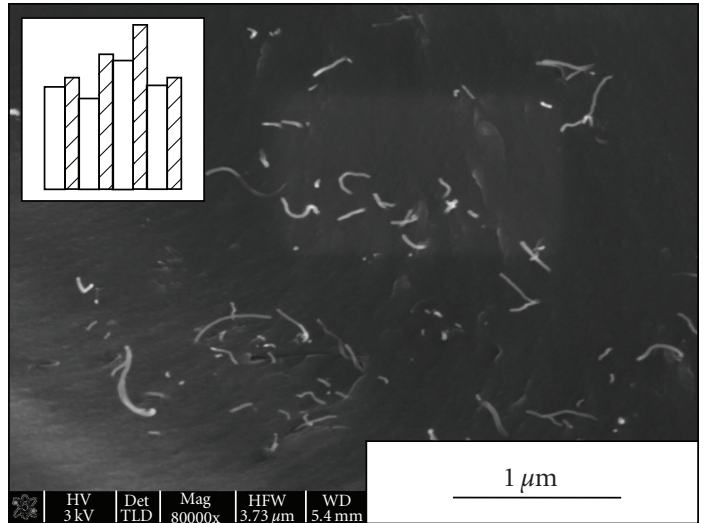

(b)

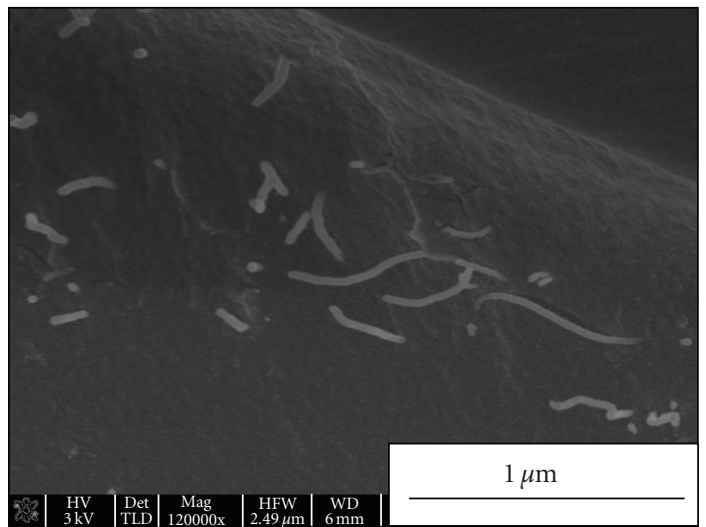

(d)

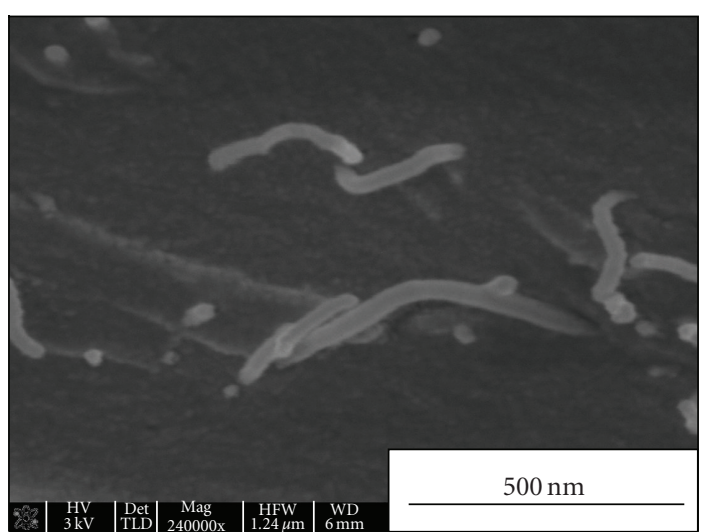

(f)

FIGURE 8: FEG-SEM micrographs of nanocomposites reinforced with $0.25 \mathrm{wt} \%$ : precured at $130^{\circ} \mathrm{C}$ for 1 hour (a, b, c) and nonprecured (d, e, f). Schemes of fracture modes inside Figures 8(a) and 8(d).

reaction follows an autocatalytic mechanism. The chemical reaction of epoxy monomer implies the aperture of an oxyrane ring forming a hydroxyl group, which can act in turn as catalyser through the weakening of nonreacted epoxy groups through hydrogen bonds. Kamal and Sourour [27] proposed an equation to describe the autocatalytic kinetic model:

$$
\frac{d \alpha}{d t}=\left(K_{1}+K_{2} \alpha^{m}\right)\left(\alpha_{\max }-\alpha\right)^{n}
$$

where $\alpha_{\max }$ is the maximum reached conversion, $K_{1}, K_{2}$ are the kinetic constants and $m, n$ are the reaction partial orders of noncatalyzed and autocatalyzed processes, respectively.

This model rightly fits the experimental data, as it is shown in Figure 9. Light deviations are observed at the end of reaction related with the hypothesis associated to autocatalytic kinetic model [27, 28]. Among others, it is assumed that the reactivity of primary and secondary amines is the same, when it is very probable that the 


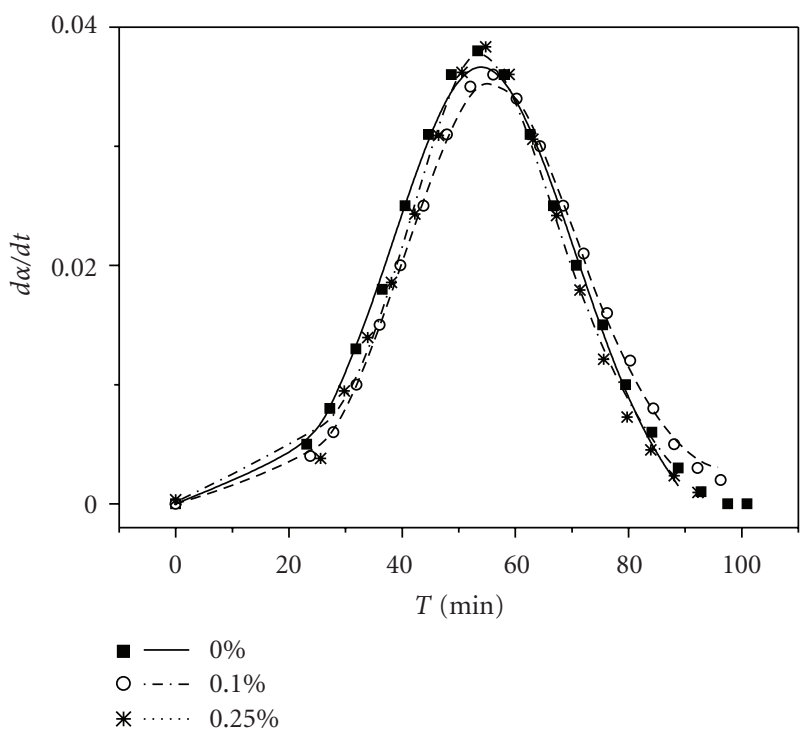

FIGURE 9: Comparison of experimental data (dotted curves) with the kinetic model data (lines) for the isothermal curing of neat epoxy resin $(0 \%)$ and nanocomposites reinforced with 0.1 and 0.25 wt $\%$ CNTs.

TABLE 3: Kinetic parameters from isothermal DSC thermograms.

\begin{tabular}{lccccc}
\hline $\begin{array}{l}\text { wt\% } \\
\text { CNTs }\end{array}$ & $\alpha_{\max }$ & $K_{1} \times 10^{2}$ & $K^{2} \times 10$ & $m$ & $n$ \\
\hline \multicolumn{5}{c}{$r=1.0$} \\
\hline 0 & 0.83 & $1.09 \pm 0.02$ & $3.42 \pm 0.08$ & $1.14 \pm 0.16$ & $2.04 \pm 0.15$ \\
0.1 & 0.81 & $1.05 \pm 0.03$ & $1.81 \pm 0.03$ & $0.99 \pm 0.09$ & $1.91 \pm 0.16$ \\
0.25 & 0.82 & $0.96 \pm 0.05$ & $3.36 \pm 0.07$ & $1.27 \pm 0.12$ & $2.07 \pm 0.09$ \\
\hline
\end{tabular}

secondary amines present lower reactivity due to higher steric hindrance. This simplification significantly affects at high values of conversion.

All-obtained kinetic parameters are listed in Table 3. The partial orders remain constant with values close to 1 and 2 , as corresponding with epoxy/amine curing reaction [27]. The noncatalytic constant, $K_{1}$, does not vary either by the CNTs addition. In contrast, the autocatalytic constant, $K_{2}$, decreases for curing of epoxy nanocomposites regard to the one of neat epoxy resin. As expected, the effect of CNTs is more marked when the percentage added is $0.10 \mathrm{wt} \%$. This decrease means that the retardation effect of carbon nanotubes is mainly related with the decrease of autocatalytic process. This is justified because the presence of nanoreinforcements with a very high-specific area hinders the formation of the ternary epoxy-hydroxyl-amine complex proposed for the catalytic reaction $[11,28]$.

After isothermal and dynamic DSC treatments, the cured samples were immediately heated into calorimeter from room temperature to $250^{\circ} \mathrm{C}$ in order to determine their glass transition temperature $\left(T_{g}\right)$. The obtained results are collected in Table 4.

The first observation is that the $T_{g}$ values of samples cured by isothermal DSC test are lower than the ones of
TABle 4: $T_{g}\left({ }^{\circ} \mathrm{C}\right)$ values of neat and nanoreinforced epoxy resins after DSC treatment.

\begin{tabular}{|c|c|c|c|c|}
\hline \multirow[b]{2}{*}{ wt $\%$ CNTs } & \multicolumn{3}{|c|}{ Dynamic DSC } & Isothermal DSC \\
\hline & $r=1.0$ & $r=1.2$ & $\begin{array}{c}r=1.0 \\
* \text { precured at } 130^{\circ} \mathrm{C}\end{array}$ & $r=1.0$ \\
\hline 0 & 142.4 & 163.7 & - & 116.6 \\
\hline 0.1 & 135.4 & 158.3 & 171.8 & 113.0 \\
\hline 0.25 & 157.7 & 172.1 & 165.8 & 122.3 \\
\hline
\end{tabular}

* DGEBA/CNTs mixtures were heated at $130^{\circ} \mathrm{C}$ for 1 hour before the curing agent addition.

samples cured through dynamic DSC treatments. This result was expected because the reached conversion, determined by the reaction heat, is lower (Tables 1 and 2). In fact, a small postcuring peak was observed in the thermograms after the glass transition when the samples were cured at $100^{\circ} \mathrm{C}$ for 1 hour. Due to the vitrification effect, the reached $T_{g}$ values are lightly higher than the curing temperature. Any residual exothermic peak was observed during the second scan of the dynamical cured mixtures, meaning that the maximal conversion was reached in the first scan in spite of the relative low $T_{g}$ obtained $\left(142^{\circ} \mathrm{C}\right.$ for stoichiometric network). On the other hand, comparing the $T_{g}$ values of neat epoxy resins with different DGEBA/DDM ratio, it is observed that in the case of the sample with amine excess $(r=1.2)$, this temperature is higher. This is again in agreement with the measured values of reaction heat in the first DSC scan, collected in Table 1.

Analysing the effect of CNTs on the glass transition temperature of epoxy matrix, it is noticed, in all studies cases, an important increase of its value regard to the $T_{g}$ of neat epoxy resin in spite of the lower values measured of the reaction heat for the nanocomposites. The increase of $T_{g}$ of epoxy matrix by the addition of carbon nanoreinforcements has been already reported by numerous authors $[8-10,15,29$, 30]. The explanation lies in the restriction of the thermally induced molecular motion of epoxy network by the addition of CNTs. In fact, this increase is much more marked for the epoxy nanocomposites whose CNTs/DGEBA mixtures were previously thermally treated in order to enhance the chemical reaction between amino-functionalized nanotubes and epoxy prepolymer. The covalent bonds between the nanofiller and the matrix reduce more the matrix mobility which results in a shift of the $T_{g}$ at higher temperatures. This result confirms that the thermal precuring treatment increases the extension of reaction between matrix and the nanoreinforcements. The formation of covalent bonds between both must enhance the load transfer from the matrix to carbon nanotubes, increasing the stiffness and mechanical the strength of the nanocomposites.

\section{Conclusions}

A DSC study of the curing kinetic of the epoxy resins reinforced with amino-functionalized carbon nanotubes has been carried out. Different parameters, such as the thermal treatment applied, the amine/epoxy ratio and the CNTs 
amount added, have been modified in order to determine the effect of nanotubes on the curing behaviour. The hypothesis proposed to explain the obtained results has been confirmed through the studies by electron microscopies (SEM, TEM, FEG-SEM) and by molecular simulation tools. The main conclusions drawn are the following.

(1) The presence of CNTs has a retardation effect on the epoxy curing reaction.

(2) The adsorption of curing agent molecules inside the nanotubes causes a decrease of reaction heat for the epoxy nanocomposites.

(3) A thermal precuring treatment applied on the mixtures of epoxy prepolymer and CNTs before curing treatment favours the formation of covalent bonds between epoxy matrix and amino-functionalized CNTs, generating a strong interface.

(4) The retardation effect of CNTs is mainly associated to the decrease of autocatalytic constant due to the higher difficulty to form ternary complexes.

(5) The glass transition temperature of epoxy matrix increases by the addition of CNTs due to the restriction of its mobility. This hindrance is higher when the reaction of amino-functionalized CNT and epoxy matrix is favoured through a precuring thermal treatment, causing a higher increase of its $T_{g}$.

\section{Acknowledgments}

The authors want to thank the participation of Patricia Recuero and the financial support of Ministerio de Educación y Ciencia of Spain (MAT2007-61178). M. R. Gude thanks Consejería de Educación de la Comunidad de Madrid (Spain) and Fondo Social Europeo for awarding a research contract.

\section{References}

[1] J. N. Coleman, U. Khan, W. J. Blau, and Y. K. Gun'ko, "Small but strong: a review of the mechanical properties of carbon nanotube-polymer composites," Carbon, vol. 44, no. 9, pp. 1624-1652, 2006.

[2] W. Bauhofer and J. Z. Kovacs, "A review and analysis of electrical percolation in carbon nanotube polymer composites," Composites Science and Technology, vol. 69, no. 10, pp. 14861498, 2009.

[3] E. T. Thostenson, C. Li, and T.-W. Chou, "Nanocomposites in context," Composites Science and Technology, vol. 65, no. 3-4, pp. 491-516, 2005.

[4] M. Abdalla, D. Dean, D. Adibempe, E. Nyairo, P. Robinson, and G. Thompson, "The effect of interfacial chemistry on molecular mobility and morphology of multiwalled carbon nanotubes epoxy nanocomposite," Polymer, vol. 48, no. 19, pp. 5662-5670, 2007.

[5] M. Moniruzzaman, F. Du, N. Romero, and K. I. Winey, "Increased flexural modulus and strength in SWNT/epoxy composites by a new fabrication method," Polymer, vol. 47, no. 1, pp. 293-298, 2006.

[6] L. Valentini, D. Puglia, F. Carniato, E. Boccaleri, L. Marchese, and J. M. Kenny, "Use of plasma fluorinated single-walled carbon nanotubes for the preparation of nanocomposites with epoxy matrix," Composites Science and Technology, vol. 68, no. 3-4, pp. 1008-1014, 2008.

[7] W. Chen, M. L. Auad, R. J. J. Williams, and S. R. Nutt, "Improving the dispersion and flexural strength of multiwalled carbon nanotubes-stiff epoxy composites through $\beta$-hydroxyester surface functionalization coupled with the anionic homopolymerization of the epoxy matrix," European Polymer Journal, vol. 42, no. 10, pp. 2765-2772, 2006.

[8] J. Shen, W. Huang, L. Wu, Y. Hu, and M. Ye, "The reinforcement role of different amino-functionalized multi-walled carbon nanotubes in epoxy nanocomposites," Composites Science and Technology, vol. 67, no. 15-16, pp. 3041-3050, 2007.

[9] X. Chen, J. Wang, M. Lin, W. Zhong, T. Feng, X. Chen, J. Chen, and F. Xue, "Mechanical and thermal properties of epoxy nanocomposites reinforced with amino-functionalized multiwalled carbon nanotubes," Materials Science and Engineering A, vol. 492, no. 1-2, pp. 236-242, 2008.

[10] J. Wang, Z. Fang, A. Gu, L. Xu, and F. Liu, "Effect of amino-functionalization of multi-walled carbon nanotubes on the dispersion with epoxy resin matrix," Journal of Applied Polymer Science, vol. 100, no. 1, pp. 97-104, 2006.

[11] M. Opalicki, J. M. Kenny, and L. Nicolais, "Cure kinetics of neat and carbon-fiber-reinforced TGDDM/DDS epoxy systems," Journal of Applied Polymer Science, vol. 61, no. 6, pp. 1025-1037, 1996.

[12] J. Bae, J. Jang, and S.-H. Yoon, "Cure behavior of the liquidcrystalline epoxy/carbon nanotube system and the effect of surface treatment of carbon fillers on cure reaction," Macromolecular Chemistry and Physics, vol. 203, no. 15, pp. 2196-2204, 2002.

[13] M. Harsch, J. Karger-Kocsis, and M. Holst, "Influence of fillers and additives on the cure kinetics of an epoxy/anhydride resin," European Polymer Journal, vol. 43, no. 4, pp. 1168-1178, 2007.

[14] L. Valentini, D. Puglia, E. Frulloni, I. Armentano, J. M. Kenny, and S. Santucci, "Dielectric behavior of epoxy matrix/singlewalled carbon nanotube composites," Composites Science and Technology, vol. 64, no. 1, pp. 23-33, 2004.

[15] A. Terenzi, C. Vedova, G. Lelli, J. Mijovic, L. Torre, L. Valentini, and J. M. Kenny, "Chemorheological behaviour of doublewalled carbon nanotube-epoxy nanocomposites," Composites Science and Technology, vol. 68, no. 7-8, pp. 1862-1868, 2008.

[16] S. G. Prolongo, M. Burón, M. R. Gude, R. Chaos-Morán, M. Campo, and A. Ureña, "Effects of dispersion techniques of carbon nanofibers on the thermo-physical properties of epoxy nanocomposites," Composites Science and Technology, vol. 68, no. 13, pp. 2722-2730, 2008.

[17] S. G. Prolongo, M. R. Gude, and A. Ureña, "Synthesis and characterisation of epoxy resins reinforced with carbon nanotubes and nanofibers," Journal of Nanoscience and Nanotechnology, vol. 9, no. 10, pp. 6181-6187, 2009.

[18] E. A. Turi, Ed., Thermal Characterisation of Polymeric Materials, Academic Press, London, UK, 1997.

[19] A. Hale, C. W. Macosko, and H. E. Bair, "Glass transition temperature as a function of conversion in thermosetting polymers," Macromolecules, vol. 24, no. 9, pp. 2610-2621, 1991.

[20] J. Jang, J. Bae, and K. Lee, "Synthesis and characterization of polyaniline nanorods as curing agent and nanofiller for epoxy matrix composite," Polymer, vol. 46, no. 11, pp. 3677-3684, 2005. 
[21] K. Yang, M. Gu, Y. Jin, G. Mu, and X. Pan, "Influence of surface treated multi-walled carbon nanotubes on cure behavior of epoxy nanocomposites," Composites Part A, vol. 39, no. 10, pp. 1670-1678, 2008.

[22] Z. Wang, Z. Liang, B. Wang, C. Zhang, and L. Kramer, "Processing and property investigation of single-walled carbon nanotube (SWNT) buckypaper/epoxy resin matrix nanocomposites," Composites Part A, vol. 35, no. 10, pp. 1225-1232, 2004.

[23] L. Valentini, I. Armentano, D. Puglia, and J. M. Kenny, "Dynamics of amine functionalized nanotubes/epoxy composites by dielectric relaxation spectroscopy," Carbon, vol. 42, no. 2, pp. 323-329, 2004.

[24] K. Horie, H. Hiura, M. Sawada, I. Mita, and H. Kambe, "Calorimetric investigation of polymerization reactions. III. Curing reaction of epoxides with amines," Journal of Polymer Science Part A, vol. 8, no. 6, pp. 1357-1372, 1970.

[25] D. Hull, An Introduction to Composite Materials, Cambridge University Press, Cambridge, UK, 1985.

[26] C. A. May, Epoxy Resins: Chemistry and Technology, Marcel Dekker, New York, NY, USA, 1988.

[27] M. R. Kamal and S. Sourour, "Kinetics and thermal characterisation of thermoset cure," Polymer Engineering \& Science, vol. 13, no. 1, pp. 59-64, 1973.

[28] A. Serier, J. P. Pascault, and L. T. My, "Reactions in aminosilane-epoxy prepolymer systems. I. Kinetics of epoxyamine reactions," Journal of Polymer Science Part A, vol. 29, no. 2, pp. 209-218, 1991.

[29] Y.-K. Choi, Y. Gotoh, K.-I. Sugimoto, S.-M. Song, T. Yanagisawa, and M. Endo, "Processing and characterization of epoxy nanocomposites reinforced by cup-stacked carbon nanotubes," Polymer, vol. 46, no. 25, pp. 11489-11498, 2005.

[30] Y. Zhou, F. Pervin, L. Lewis, and S. Jeelani, "Experimental study on the thermal and mechanical properties of multiwalled carbon nanotube-reinforced epoxy," Materials Science and Engineering A, vol. 452-453, pp. 657-664, 2007. 

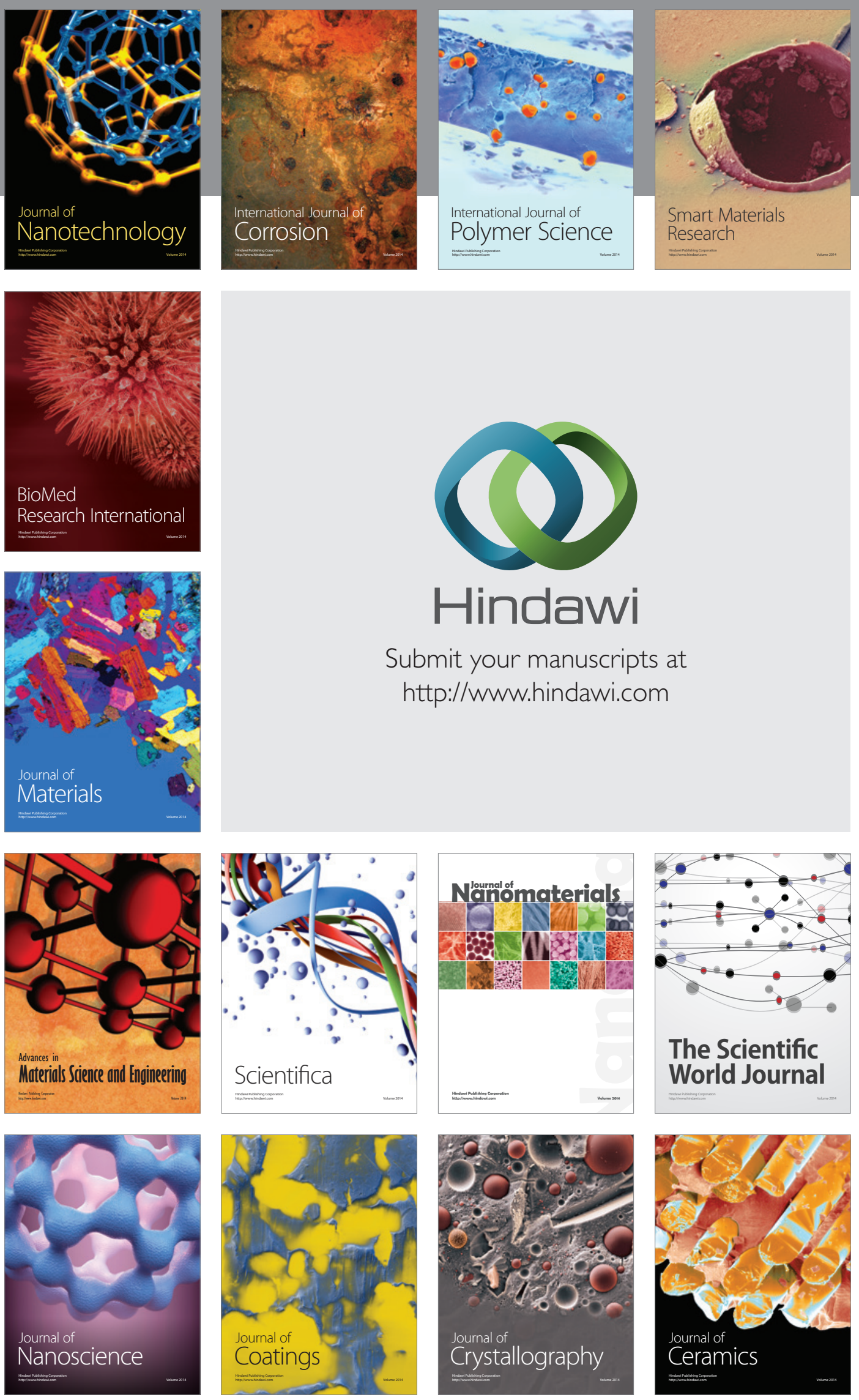

The Scientific World Journal

Submit your manuscripts at

http://www.hindawi.com

\section{World Journal}

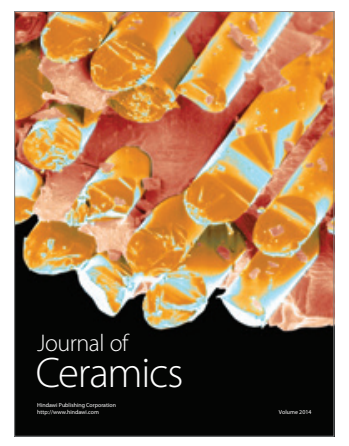

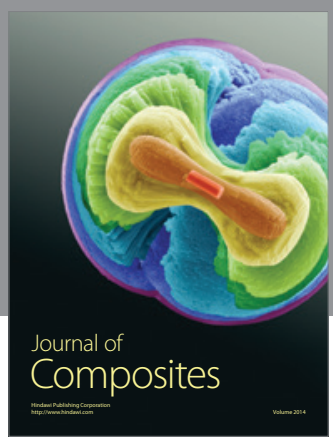
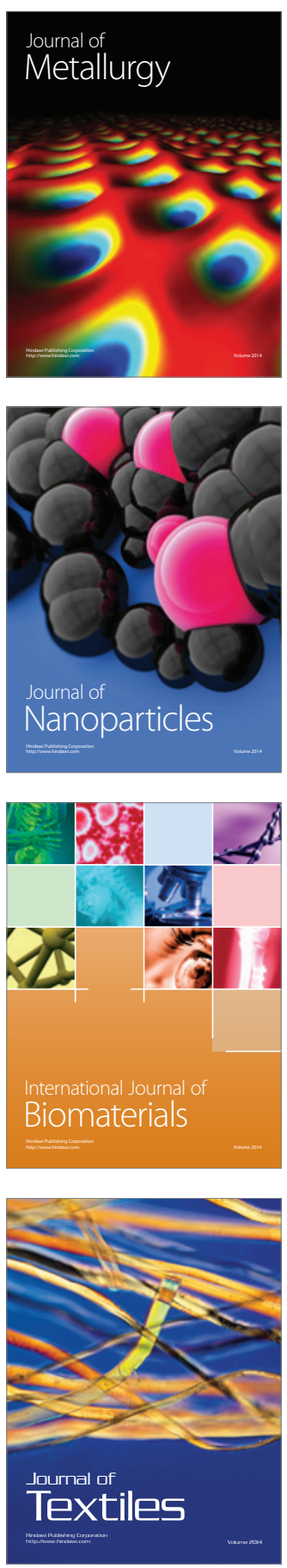